\title{
Academic Stress as A Health Measure and Its Relationship to Patterns of Emotion in Collectivist and Individualist Cultures: Similarities and Differences
}

\author{
Reza Kormi-Nouri ${ }^{1}$, Shane MacDonald ${ }^{2,3}$, Mohammad-Naghy Farahani ${ }^{4}$, Kari Trost $^{5}$ \& Omid Shokri ${ }^{6}$ \\ ${ }^{1}$ Center for Health and Medical Psychology, Örebro University, Sweden \\ ${ }^{2}$ Psychological Links of Unique Strengths, Stockholm University, Sweden \\ ${ }^{3}$ Network for Empowerment and Well-being, Gothenburg University, Sweden \\ ${ }^{4}$ Dept. of Psychology, Kharazmi University, Tehran, Iran \\ ${ }^{5}$ Dept. of Child \& youth studies, Stockholm University, Sweden \\ ${ }^{6}$ Dept. of Psychology, Shahid Beheshti University, Tehran, Iran \\ Correspondence: Reza Kormi-Nouri, Center for Health and Medical Psychology, Örebro University, Örebro, 70182 , \\ Sweden. Tel: 46-19-301293. E-mail: reza.kormi-nouri@oru.se
}

Received: February 25, 2015

Accepted: March 16, 2015

Online Published: March 17, 2015

doi:10.5430/ijhe.v4n2p92

URL: http://dx.doi.org/10.5430/ijhe.v4n2p92

\begin{abstract}
The present study investigates academic stress in two different cultures, the Iranian as a collectivist culture, and the Swedish as an individualist culture. A total of 616 university students (312 Iranian and 304 Swedish) participated in the study. The results show that Swedish students experience more academic stress than Iranian students. Academic stress was found to be related to difficulties in and outside class, and managing work, family and leisure activities. There was no cultural difference in terms of interacting with the university administration, teachers and friends. There was a gender difference, with females experiencing more academic stress than males, an effect that was more pronounced in Sweden than in Iran. Subset analyses (92 Swedes and 100 Iranians) revealed a tendency of Iranian students to balance positive and negative emotions in comparison to students from Sweden. Partial correlations showed that negative affect was the sole affect to significantly correlate with academic stress in Sweden. Negative and positive affect correlated in unison with academic stress in Iran. These results are discussed on an individualist-collectivist dimension. Cultural differences between the educational systems in the two countries may also explain the differing emotion/affect-health relationships.
\end{abstract}

Keywords: Academic stress, Collectivist culture, Individualist culture, Emotional expression

\section{Introduction}

Studies of general experienced stress have failed to illustrate strong relationships between stress and academic outcomes. Following the argument of Zajacova, Lynch, and Espenshadet (2005), it was found that life-event stress did not predict the academic performance of college student athletes (Petrie and Stoever, 1997), and perceived stress was not a significant predictor of the intent to stay in school of adult college students (Sandler, 2000). However, the picture is different for academic stress, which is regarded as an important factor in adjustment to university life and has been studied extensively (Gall, Evans, \& Bellerose, 2000; Mallinckrodt, 1988). In general, academic stress and academic performance are inversely related among different groups of participants: metropolitan high school students (Gillock \& Reyes, 1999), immigrant university students (Buddington, 2002), and diverse cohorts of traditional undergraduates (Felsten \& Wilcox, 1992; Pritchard \& Wilson, 2003; Russell \& Petrie, 1992; Struthers, Perry, \& Menec, 2000). Academic stress has been linked to lower academic grades, and also to lower persistence among university freshmen (Perrine, 1999; Zhang, \& RiCharde, 1998) and older non-traditional students (Chartrand, 1992). Academic stress is of clear importance for young adults today. Why is this problem important?

Stress is subjective, which makes it important to consider the environments in which it arises. Being in a collectivist or individualist context may be a determinant of the experience of academic stress. Indeed, there is much research on differences between individuals from collectivist and individualist cultures with regard, inter alia, to perceptions (Chua, 
Boland \& Nisbett, 2005; Masuda \& Nisbett, 2006), values (Triandis, 1990), emotions (Kormi-Nouri, Farahani \& Trost, 2013; Markus \& Kitayama 1991), emotional reactivity (Chentsova-Dutton \& Tsai, 2010), and having an autonomous orientation (Jobson, 2011). From a cultural perspective, Markus and Kitayama (1991) were pivotal in stimulating a number of studies within the area of emotional differences. Based on the idea of social orientation, many differences have been found between and within cultures.

One reason for the differences stems from the idea that in collectivist cultures, feeling stressed is not only the concern of the individual but also of the group, since attention has to be paid to the individual's unique feelings (Markus \& Kitayama, 1994). It has been found that Asian Americans report more relational than individual-focused attention than their European-American counterparts (Chentsova-Dutton \& Tsai, 2010). Further, it has recently been postulated that cultural differences in emotions may be driven by attention-related tendencies linked to the processing of diverse information (Grossmann, Ellsworth, \& Hong, 2012).

Some cultures may simply be more biased toward more negative experiences than others. For example, Grossmann and Kross (2010) reported that Russians are more likely than Americans to focus on negative experiences. And, in another comparative experimental study examining the negative focus of individuals identifying with Russian culture, Grossmann et al. (2012) reported that Russian participants looked at negative pictures for longer than they did positive ones. This effect was not found for their American counterparts, or even for their Russian-Latvian counterparts (who identified less with Russian culture). In a recent study (Kormi-Nouri et al., 2013), it was shown that Swedish undergraduate students showed more positive emotions than Iranian undergraduate students, whereas Iranian undergraduates showed more negative emotions than Swedish undergraduates.

By pursuing the status quo, collectivists affirm the importance of both the group's values and group affiliation. With a focus on social cohesion, people from collectivist cultures incline to self-criticism as a way of improving themselves and, in turn, their group (Heine, Lehman, Markus, \& Kitayama, 1999). Collectivist cultures tend to be more socially oriented, and place emphasis on a person's immediate group and on the significant relationships between members of that group (Compton, 2005; Kitayama, Markus \& Kurokawa, 2000). Western European countries are viewed as individualist, where individuals tend to place greater emphasis on individualism, autonomy, freedom of expression, and self-enhancement. This, however, should not be interpreted to mean that individualists engage in self-enhancement more than their collectivist counterparts. There is some disagreement in the literature on this. For example, Brown and Kobayashi posit that self-enhancement is a universal attribute, and also a sign of mental health. And meta-analyses have been used to show that collectivists are no less likely to self-enhance than individualists from Western societies (Mezulis, Abramson, Hyde, \& Hankin, 2004; Sedikides, Gaertner, \& Vevea, 2007). That stated, however, support for the claim that collectivists do not self -enhance has been found in other meta-analyses (Heine \& Hamamura, 2007; Heine, Kitayama, \& Hamamura, 2007).

For the present study, a cross-sectional analysis was performed to determine the prevalence of academic stress among university students and examine associations between domains of academic stress, i.e. the sources of stress. Academic stress was investigated among university students. Due to an increasing interest for the cultural relationships between emotions and health (Pressman, Gallagher and Lopez, 2013). Comparisons were made between academic stress as a health measure and its relationship to patterns of emotion in Sweden as an individualistic culture and their counterparts in Iran as a collectivist country.

Previous research has shown some cultural differences between American students and international or immigrant students with regard to academic stress (Misra \& Castillo, 2004), and to the impact of social stress on academic outcomes (Moritsugu \& Stanley, 1983; Smedley, Myers, \& Harrell, 1993). However, there has been little research into academic stress in relation to the collectivist-individualist dimension. By studying specific types of academic stress from stress experienced in the classroom to stress emanating from an imbalance between university and other aspects of life in different contexts - we illuminate the relationships between academic stress and various stress-related outcomes, and show how they may or may not differ according to culture. By looking at academic stress in Sweden and Iran, we gain knowledge not only of what academic stress is like among university students, but also of whether there are differences depending on type of academic stress, gender, and culture.

\section{Method}

\subsection{Participants}

The participants were 304 Swedish undergraduate university students (96 males and 208 females) and 312 Iranian undergraduate university students (92 males and 220 females). The students were selected from diverse academic disciplines (e.g., psychology, education, technology and engineering, nursing, and business). As shown in Table 1, the 
students in the Swedish student sample were slightly older than their Iranian counterparts, and the

Table 1. Demographic information about the participants by country

\begin{tabular}{lll} 
& Sweden & Iran \\
\hline $\mathrm{N}$ & $304(96$ male, 208 female $)$ & $312(92$ male, 220 female $)$ \\
Age & $23.45(\mathrm{SD}=4.13)$ & $21.52(\mathrm{SD}=2.25)$ \\
& Range: $19-41$ & Range: $18-33$ \\
Employed & Yes: $40 \% / \mathrm{No}: 60 \%$ & Yes: $5 \% /$ NO: $95 \%$ \\
Married (cohabiting) & Yes: $40.6 \% /$ No: $59.4 \%$ & Yes: $8 \% /$ No: $92 \%$ \\
\hline
\end{tabular}

variability in age was greater in Sweden than in Iran. Correlations between academic stress and indices of negative and positive affect were conducted. The affective profiles approach has been extensively used (Archer, Adrianson, Plancak, $\&$ Karlsson, 2007) together with the PANAS measure and a median split method to divide diverse populations into four groups. The groups are high on one affect and low on the other (self-actualizing or self-destructive). Alternatively the groups are either high or low on both affects (high affective or low affective).

A person-oriented cluster analysis is an alternative to the use of median splits as a method of categorization. This method capitalizes on existing structure in the data and may therefore be more appropriate for gender and cultural comparisons than imposing structure on data without consideration of existing structure in that data. Person oriented analyses using Ropstat (Vargha, Torma and Bergman, 2014) and the affective profiles approach (Garcia \& MacDonald, working paper) was used on a subset of individuals (100 Swedes and 92 Iranians) to inspect cultural differences in emotional expression.

\subsection{Measurments}

To measure academic stress, 27 questions were posed to the students on the basis of the academic tasks listed in an American instrument (Zajacova, Lynch \& Espenshadet, 2005). We used this instrument because it is suitable for university students and includes different sorts of academic stress. Students were asked to report how stressed they felt in relation to a range of items, such as "writing term papers", "asking questions in class", and "managing both school and work." Responses for each task were on an 11-point Likert-type scale from 0 (not at all stressful) to 10 (extremely stressful). An additional item was added to the original academic-stress scale concerning stress experienced in the task of managing leisure activities, with responses on the same 11-point Likert-type scale, which resulted in a total of 28 questions being posed to the university students. In line with the study by Zajacova et al. (2005), the items were clustered around four subscales: a) difficulties with academic performance in class, b) difficulties with academic performance outside class, c) difficulties in interacting with people in the university, d) difficulties in managing different domains (work, family, and leisure). The 28 items and their subsets are shown in the Appendix. Cronbach's alpha coefficients were .90 for the Swedish students, and .95 for the Iranian students. These reliability scores were deemed acceptable on the basis of the results of previous studies using the English version.

To measure positive and negative emotion a measure of positive and negative affective states (Watson, Clark \& Tellegen, 1998) was used. The scale contains 10 positive (interested, excited, strong, enthusiastic, proud, alert, inspired, determined, attentive, active) and 10 negative (distressed, upset, guilty, scared, hostile, irritable, ashamed, nervous, jittery, afraid) verbal descriptors. Responses were scored on five-point likert type scales and added to get a total score. Cronbach's alpha reliability coefficients showed an acceptable 0.76 (Iranians) and 0.78 (Swedes) for positive affect, and 0.70 (Iranians) and 0.72 (Swedes) for negative affect. Further research is needed to investigate robustness of its psychometric properties. The PANAS differs from other self-report measures of emotion in that the positive and negative scales are not designed to tap contemporary notions of subjective emotional expression (Diener et al., 2010; Pressman et al., 2013). Neither have they been found to correlate with each other. We deem the use of the word emotion to be synonymous with the word affect for the purpose of the present study.

All questionnaires were translated from English to Swedish and Persian and also back-translated as a check on accuracy of the translations.

\section{Results}

The descriptive results are shown in Table 2. In general, the Swedish students reported more academic stress regardless of type of stress, which meant higher levels of total academic stress for the Swedish than the Iranian participants. 
Table 2. Means and standard deviations (SD) on the total academic stress scale and its subscales by country and gender. Sweden Iran

\begin{tabular}{lllll}
\hline Type & Male & Female & Male & Female \\
\hline In class & & & & \\
Mean score (\%) & $29.67(49.5 \%)$ & $35.13(58.5 \%)$ & $26.25(44 \%)$ & $31.83(53 \%)$ \\
SD & 9.23 & 9.64 & 11.99 & 14.40 \\
Outside class & & & & \\
Mean score (\%) & $42.88(53.6 \%)$ & $47.51(59.4 \%)$ & $27.02(34 \%)$ & $31.90(40 \%)$ \\
SD & 12.26 & 12.58 & 13.26 & 16.06 \\
Interacting with the university & & & \\
Mean score (\%) & $26.92(33.6 \%)$ & $29.12(36.4 \%)$ & $25.39(31.7 \%)$ & $26.98(33.7 \%)$ \\
SD & 13.54 & 12.83 & 15.19 & 16.17 \\
Managing work, family & $\&$ leisure & & & $18.71(31.2 \%)$ \\
Mean score (\%) & $26.11(43.5 \%)$ & $33.50(55.8 \%)$ & 9.27 & 11.01 \\
SD & 10.77 & 10.55 & & \\
Total academic stress & & & $97.37(34.77 \%)$ & $112,71(40.2 \%)$ \\
Mean score (\%) & $125,95(45 \%)$ & $145,13(51.8 \%)$ & 44.23 & 51.36 \\
SD & 38.20 & 35.75 & &
\end{tabular}

Note: Percentage refers to the mean score as a percentage of the maximum score. The maximum scores for each of the subscales are: in class $=60$, outside class $=80$, interacting with the university $=80$, managing work, family $\&$ leisure $=$ 60 , which give a total maximum score of 280 .

A 2 (Culture) by 2 (Gender) ANOVA was conducted on the total academic-stress scores. The analysis revealed both gender- and culture-related effects. A main effect was found for culture as a whole, where Swedish students (M = $139.09=49.67 \%)$ reported more academic stress than Iranian students $(\mathrm{M}=105.04=37.51 \%), \mathrm{F}(1,612)=43.66$, $\mathrm{MSe}=3465.43, \mathrm{P}<.001$. And a main effect was also found for gender, where female university students $(\mathrm{M}=132.14$ $=47.2 \%$ ) reported more academic stress than male university students $(\mathrm{M}=111.99=40 \%), \mathrm{F}(1,612)=15.30, \mathrm{MSe}=$ $3465.43, \mathrm{P}<.05$. However, no effect of interaction between the gender and culture variables was found, $\mathrm{F}(1,612)$ $=.87, \mathrm{MSe}=3465,43, \mathrm{p}>.50$.

We then entered culture and gender as independent variables, and the four stress subscales as dependent variables, into a MANOVA (summarized in Table 3).

Table 3. Domain-specific academic stress: differences and similarities by culture and gender.

\begin{tabular}{lllll} 
Variable & df & F & MSe & P \\
\hline Culture & & & & \\
Difficulties in class & 1,598 & 10.53 & 142.38 & $<.001$ \\
Difficulty outside class & 1,598 & 164.24 & 194.23 & $<.001$ \\
Difficulties with university & 1,598 & 1.45 & 1836.73 & $>.20$ \\
Difficulties in managing & 1,598 & 110.19 & 109.61 & $<.001$ \\
Gender & 1,598 & 25.38 & 142.38 & $<.001$ \\
Difficulties in class & 1,598 & 15.25 & 194.24 & $<.001$ \\
Difficulties outside class & 1,598 & 1.51 & 1836.73 & $>.20$ \\
Difficulties with university & 1,598 & 35.40 & 109.61 & $<.001$ \\
Difficulties in managing & 1,598 & .66 & 1206.75 & $>.40$ \\
Culture x Gender & & & & \\
\hline
\end{tabular}


The MANOVA showed that there were significant differences between the Swedish and Iranian university students in all the domains of academic stress, except that concerning interacting with people at the university. Similar differences were found with regard to gender. Again, male university students and female university students differed in all the academic stress domains, except that concerning interacting with people in the university. The differences for interacting with the university were not significant on either the country or the gender variable. Once again, inter-variable interaction (between culture and gender) was found to be non-significant ( $\mathrm{ps}>.10$ ).

Our subset of data showed that positive and negative emotions correlate with academic stress. Although in Iran both positive and negative emotions statistically significantly correlated with academic stress at the same time. In both cultures positive and negative emotions correlated negatively. These correlations are shown in table 4.

Table 4. Cultural comparisons between emotion and academic stress

Country Correlations Partial correlations*

PE correlated with NE

\begin{tabular}{|c|c|c|c|c|c|}
\hline & $\underline{\mathrm{PE}}$ & $\underline{\mathrm{NE}}$ & $\underline{\mathrm{PE}}$ & $\underline{\mathrm{NE}}$ & \\
\hline $\begin{array}{l}\text { Iran } \\
(\mathrm{N}=100)\end{array}$ & $-0,04$ & $0,316^{* *}$ & $-0,313 * *$ & $0,358^{* *}$ & $-0,260 * *$ \\
\hline $\begin{array}{l}\text { Sweden } \\
(\mathrm{N}=92)\end{array}$ & $-0,313 * *$ & $0,358 * *$ & $-0,04$ & $0,316^{* *}$ & $-0,308 * *$ \\
\hline
\end{tabular}

Note * $\mathrm{PE}=$ Positive emotion, $\mathrm{NE}=$ Negative emotion. Partial correlations remove one emotion from the other when correlating with academic stress.

A chi-square test $(\mathrm{p}<.10$ level) on percentages revealed a tendency for people to balance affect in Iran compared to Sweden $\left(\mathrm{X}^{2}(3)=6.46 . \mathrm{p}=.09\right)$. This statement is supported by the observation that being high on negative emotions and low on positive emotions appeared uncommon in the Swedish sample relative to the Iranian sample. Using the affective profiles approach people in a collectivistic culture rarely formed a 'self-destructive' and homogenous group with regard to low positive and high negative affect. Iranian students extremely high on negative emotions were relatively low on positive emotions (compared to their Swedish counterparts). A group is considered as being homogenous if the homogeneity co-efficient is under 1 (Bergman, Magnusson \& El Khouri, 2003). The groups derived from cluster analyses are shown in tables 5 and 6 . The analyses showed a clear cultural difference in the pattern of standardized means. The four cluster solution dictated by the affective profiles approach explained an acceptable average of $70 \%$ variation (Bergman et al., 2003) in independent data sets from each culture.

Table 5. Four different groups derived from cluster analysis in Iranian sample, EESS $=72,26 \%$

\begin{tabular}{lllll}
\hline & $\mathrm{N}$ & Homogeniety co-efficient & $\begin{array}{l}\text { PATTERN OF STANDARDIZED MEANS } \\
(\mathrm{H}=\text { High, L = Low })\end{array}$ \\
\hline Self-actualizing & 44 & 0,67 & $(\mathrm{H})$ & $(\mathrm{L})$ \\
Low affective & 23 & 0,46 & $\mathrm{~L}$ & $(\mathrm{~L})$ \\
High affective & 21 & 0,58 & $(\mathrm{H})$ & $\mathrm{H}+$ \\
Self destructive & 12 & 0,67 & $\mathrm{~L}++$ & $\mathrm{H}+$ \\
\hline
\end{tabular}

Notations:

Simple appearance: $0,675<=|\mathrm{z}|<=1,000$ (p: $16-25 \%)$

( ): $0,44<=|\mathrm{z}|<=0,674$ (p: $25-33 \%$ )

$+: 1,001<=|\mathrm{z}|<=1,404$ (p: $8-16 \%$ )

$++: 1,405<=|\mathrm{z}|<=1,644$ (p: $5-8 \%)$

$+++: 1,645<=|\mathrm{z}|<=2,044$ (p: $2-5 \%$ )

$++++: 2,045<=|\mathrm{z}|(\mathrm{p}: 0-2 \%)$ 
Table 6. Four different groups derived from cluster analysis in Swedish sample, EESS $=67,84 \%$

\begin{tabular}{|c|c|c|c|c|}
\hline & $\mathrm{N}$ & Homogeniety co-efficient & & $\begin{array}{l}\text { PATTERN OF STANDARDIZED MEANS } \\
(\mathrm{H}=\text { High, } \mathrm{L}=\text { Low })\end{array}$ \\
\hline Self-actualizing & 40 & 0,64 & (H) & L \\
\hline Low affective & 24 & 0,79 & $\mathrm{~L}+$ & . \\
\hline High affective & 24 & 0,45 & . & $\mathrm{H}$ \\
\hline \multirow[t]{3}{*}{ Self destructive } & 4 & 1,61 & $\mathrm{~L}+$ & \multirow{3}{*}{$\mathrm{H}^{+}$} \\
\hline & & & & \\
\hline & & & +++ & \\
\hline
\end{tabular}

Notations:

Simple appearance: $0,675<=|\mathrm{z}|<=1,000$ (p: $16-25 \%)$

( ): $0,44<=|\mathrm{z}|<=0,674$ (p: $25-33 \%$ )

$+: 1,001<=|\mathrm{z}|<=1,404$ (p: $8-16 \%)$

$++: 1,405<=|\mathrm{z}|<=1,644$ (p: $5-8 \%$ )

$+++: 1,645<=|\mathrm{z}|<=2,044$ (p: $2-5 \%$ )

$++++: 2,045<=|\mathrm{z}|(\mathrm{p}: 0-2 \%)$

\section{Discussion}

The present research set out to explore different sources of stress in collectivistic and individualistic cultures on a health measure of academic stress. We gained knowledge not only of what academic stress is like among university students, but also about differences depending on type of academic stress, distinct individual patterns of affect/emotion, gender, and culture. Generally speaking, our higher educational systems impose some kind of stress on all undergraduate university students (irrespective of gender and culture). Correlations from a subgroup of respondents showed that emotion is related to academic stress in both cultures. In Sweden, negative affect overlapped with positive affect to explain most variance in academic stress scores, while, in Iran, both positive and negative affect/emotion showed overlapping relationships and correlated in unison with academic stress. We conclude that individual differences in patterns of affect within and between cultures in emotional expression is worthy of further study.

\subsection{Academic stress}

The results, in absolute stress scores, showed that university students in both cultures experienced academic stress. These figures can be regarded as moderate, but the finding is in line with research indicating that academic stress should be regarded as an important factor in adjusting to university life (Gall et al., 2000; Mallinckrodt, 1988). On comparing the different sources of academic stress, it was found that the highest levels of academic stress were related to difficulties in class, difficulties outside class, and managing work, family and leisure activities. The lowest level of academic stress was found for difficulties in interacting with people at the university. These results indicate that the main source of stress lies in educational tasks, where students need to take responsibility for tasks which they need to perform themselves, but that there is less of a problem with regard to communications and contacts with the administration, teachers and other students in the university system. An analysis of the individual items also showed that the ones related to performances in exams and class produced the highest levels of academic stress (having more than one test in the same week; doing well in exams; preparing for exams, doing well in my toughest class; and, participating in class discussion). On the other hand, the lowest academic stress was observed on the items relating to interactions with the organization and people (understanding college regulations; talking to college staff; making friends at school; getting help and information at school; and getting along with family members). This is in line with research showing that examinations are the greatest cause of stress for undergraduate students (Abouserie, 1994). 


\subsection{Individual differences of patterns in affect/emotion}

In order to further explore earlier findings that west Asian students compared to Western European students show a tendency to balance positive and negative emotions (Kormi-Nouri et al., 2013; Leu, Wang and Koo 2011), we used the affective profiles approach (Garcia \& MacDonald, working paper). After analyzing individual patterns of emotional expression in the data, our findings were similar to those of Pressman et al. (2013) who found relationships with positive and negative emotions and their measure of physical health in Gallup poll data. In their study they chose to focus on how people may differ in their emotional expressions based on observed relationships between emotion and physical health as a function of Gross Domestic Product. From the present study together with reports from the extent litterature, we conclude that detailed subgroup analyses together with well-validated measurements may be well equipped to reflect relationships between emergent patterns of positive/negative emotions and health.

At a general population level we also found relationships between emotions and academic stress as our measure of health. However, when we partialled out one emotion from the other, our results are intriguing. A collectivistic culture is clearly associated with promoting different types of emotional expression with regards to higher academic studies than an individualistic culture. Both positive and negative emotion overlapped to explain significant amounts of variance in the academic stress of Iranian university students. In Sweden as an individualistic culture negative emotion alone explained a significant amount of variance in academic stress. These observations do not indicate that levels of positive emotions are unimportant when considering individuals and their academic stress, in Iran or Sweden. On the contary we conclude that studying correlates of different emotional/affective subtypes may shed further light on a suspected relationship between academic prestations and individual patterns of emotional expression. On the one hand the distribution of affective profiles was similar in both countries. Further systematic researches are required to probe deeper into this relationship. A research focus on variables may need to be complemented (Bergman \& Trost, 2006) with regard to the individual cases that provide data on those variables.

\subsection{Gender}

Previous research showed that female students not only experience greater academic stress (Misra \& Mckean, 2000; Abouserie, 1994), but also greater life stress (Abouserie, 1994; Dahlin, Joneborg \& Runeson, 2005; Toews et al., 1997). Once again, in the present study, the relatively greater stress among females, compared with males, was related to difficulties in class, difficulties outside class, and managing work, family, and leisure activities. All these differences were confirmed by our statistical analysis. There was no significant difference between females and males in academic stress related to difficulties in interacting with people in the university. Thus, it seems that that the source of stress that generates gender differences concerns the educational tasks for which students must take responsibility and perform by themselves. There was less of a problem with regard to communications and contacts with the administration, teachers, and other students in the university system. An analysis of individual items on each subscale showed that, on the difficulties-in-class subscale, there was no significant sex difference in academic stress related to parents' expectations with regard to grades. But, on all the other items in this subset of questions, females experienced greater academic stress than males. On the difficulties-outside-class subscale, there were no significant sex differences on half of the items ("studying", "writing term papers", "improving my reading and writing skills", and "researching term papers"). But, on the other half ("keeping up with required reading", "getting papers done on time", "preparing for exams", "understanding my textbooks"), females showed greater academic stress scores than males. On the interacting-with-the-university subscale, the only sex difference was related to "asking questions in class", where females experienced more academic stress than males. There was no sex difference on the other items related to the university subscale. On the managing-different-domains subscale, females showed significantly greater academic stress than males on all items.

Both female and male Swedish students showed greater academic stress than their female and male counterparts in Iran. Further, in both countries, female students showed greater academic stress than male students. These results also applied to three of the subscales, measuring difficulties in class, difficulties outside class, and managing work, family and leisure activities. However, there was no gender difference in academic stress related to interacting with people in the university in either country. In particular, Swedish female students experienced the greatest academic stress on total score and on all the four subscales (in class; outside class; managing work, family and leisure activities; and, interacting with the university). By contrast, Iranian male students experienced the least academic stress on total score and on all the four subscales (in class; outside class; managing work, family and leisure activities; and, interacting with the university). To explain these findings, again it can be argued that in individualist cultures (such as Sweden), with more egalitarian gender attitudes, females have greater expectations of higher education, and therefore experience greater academic stress. In line with this argument, McDaniel (2010) found in her research that young females have 
higher educational expectations than young males in many European countries. But this was not found to be the case in Asian countries, such as Japan and Korea. Further research is needed to show more clearly and systematically why females experience greater academic stress in an individualist culture.

In line with Bradley and Ramirez (1996), it can be argued that the spread of more egalitarian gender attitudes across countries can be a driving factor behind females' increasing academic stress. Further, more gender-egalitarian attitudes can increase the educational expectations of females in many countries (McDaniel, 2010), which, in turn, may be a cause of greater academic stress. Research also shows that females clearly outnumber males in university (especially in departments dedicated to the humanities), have for long outperformed males in the classroom, and have generally been rated as better students by their teachers (McDaniel, 2011; Schofer \& Meyer, 2005). But, although the upward trends in enrollment and participation in higher education have been steeper for females than males, the degree performance and educational attainment of males have been better than those of females (Pekkarinen, 2008). All these findings indicate that having a university education has become increasingly important for females, but that, at the same time, it brings greater competition and academic stress.

\subsection{Culture}

The results of this study show that, in terms of mean total scores, Swedish students experience greater academic stress than Iranian students. This finding is consistent with earlier studies that indicate some cultural differences. For example, American students have been found on average to perceive a higher level of academic stress than their international counterparts (Misra \& Castillo, 2004). In our study, the differences between Swedes and Iranians were greatest with regard to difficulties outside class, difficulties in class, and managing work, family and leisure activities. There was no difference between Swedish and Iranian students in academic stress related to difficulties in interacting with people in the university.

An analysis of the individual items showed that, on the difficulties-in-class subscale, Iranian students experienced greater academic stress on the item "my parents' expectations of my grades" than Swedish students, but, on all the other items, Swedish students showed greater academic stress than their Iranian counterparts. In the difficulties-outside-class subscale, for only one item ("researching term papers") was there no cultural difference; on all the other items, Swedish students experienced greater academic stress than Iranian students. In the case of items on the interacting-with-the-university subscale, Iranian students experienced significantly greater academic stress than Swedish students on "understanding college regulations". On the other hand, on "asking questions in class", "understanding my professors (teachers)", "talking to my professors (teachers)" and "talking to college staff", Swedish students showed greater academic stress than Iranian students. On three items - "making friends at school", "getting help and information at school", and "participating in class discussions") - there was no significant cultural difference. In the case of the managing-different-domains subscale, Swedish students experienced significantly greater academic stress than Iranian students on all items.

One possible explanation for these findings is that they are related to differences between individualist and collectivist cultures. Highly individualist cultures (such as those prevailing in the USA and Western European countries) tend to place greater emphasis on individualism, autonomy, and freedom of expression, and also on people's inner thoughts, emotions, and experiences. By contrast, collectivist cultures (such as those prevailing in east or west Asian countries like China, Japan and Iran) tend to be more socially oriented, and place emphasis on a person's group-belonging and on significant relationships between members of the group (see, for example, Compton, 2005; Markus \& Kitayama, 1994; Realo, 2003). Thus, university students in Sweden, as a Western European country, and students in Iran, as a west Asian country, may experience academic stress differently. It is possible that university students in individualist countries take on greater personal responsibility for their own performance within the educational system, and are less inclined to share their problems with others. By contrast, in collectivist countries, the educational system (e.g., the university administration, teachers) may take greater responsibility for education, and students may be more inclined to share their problems with others (friends, family, teachers, and administrators). Supporting this idea, it was shown by our analysis of individual items that Iranian students face greater academic stress on "my parents' expectations of my grades" than do Swedish students. On the other hand, Swedish students show greater academic stress on "getting the grades I want". Further, with regard to interacting with people in the university - on "asking questions in class", "understanding my professors (teachers)", talking to my professors (teachers)", and "talking to college staff" Swedish students displayed greater academic stress than their Iranian counterparts. These findings clearly show that the differences between the two samples might be explained on a collectivist-individualist dimension.

Another contribution to studying a relationship between emotion and academic stress may lie in giving consideration to individual differences in emotional expression. In addtion to drawing a conclusion that people experience academic 
stress in both cultures; Sweden and Iran. People may be predisposed to experience academic stress a little differently depending on culture. In Sweden, as an individualistic culture, academic stress and negative affect may be more strongly related than for people in Iran, as a collectivistic culture. This conclusion is based on observing correlations in Sweden opposed to the same correlations in Iran.

When we partialled out positive emotions from negative emotions from each other in bivariate correlations with academic stress. Negative emotions overlapped with positive emotions to explain the most variance in academic stress in Sweden as an individualistic culture. In Iran as a collectivisic culture both positive and negative emotions overlapped and explained academic stress in unison. This might be interpreted to mean that while in an individualistic setting positive emotions are ignored in relation to academic stress, possibly to the detriment of academic prestation.

\subsection{Measurement and design issues}

Academic stress and academic performance have been found to be inversely related among different groups of participants (e.g. Gillock \& Reyes, 1999). Academic stress has been also linked to lower academic grades, and lower persistence among university freshmen (e.g. Perrine, 1999; Zhang, \& RiCharde, 1998). In pattern-oriented analyses we were able to demonstrate the existence of individual differences in affect/emotion between and within Swedish and Iranian university students. These patterns of affect are assumed to underly patterns of individual differences (Garcia \& MacDonald, working paper) that may be related to expressions of of emotion related to academic stress. Our data indicate that some individuals may be more prone to exhibit academic stress than others. This has relevance for future research attemptimg to uncover a relationship between academic performance and academic stress.

In the present study participants were convenience sampled. Our subset of data containing information on affect/emotion was therefore suboptimal $(\mathrm{n} \leq 100)$, inhibiting detailed subgroup analyses. Hence there is a need to replicate our findings on larger samples. Relatively speaking, experiencing high negative together with low positive emotions seemed common in Iran but relatively infrequent in Sweden. Based on previous research using the affective profiles approach this could be an artifact of the sampling procedure. Visual inspection of affective profiles showed similarities in distribution of the affective profiles sampled. Larger samples are needed to obtain more homogenous groupings.

Another explanation may lie in differences between the educational systems of the two countries. In the Iranian sample, all students were on programs, whereas the majority of students in the Swedish sample worked within a free-course system. It can be argued that students on a program experience less academic stress, since the educational goals and plans are well-defined, and an academic study plan is set that requires them to pass their present courses to get to the next level. By contrast, having separate courses requires students to get high grades, so that they can compete for the courses to which they want to be admitted in the following semester. In support of this idea, in the Swedish sample, a comparison between the students who studied on a program with those who studied within a free course system demonstrated that Swedish students in a free course system showed greater academic stress than Swedish students on a program. We need to be cautious with this finding, since only a small number of the Swedish students who were on a program. Nevertheless, the finding needs to be replicated and investigated more systematically in future research.

Another issue relates to the grading systems used in the two countries. In Iran, a 21-point grading system (range: 0-20) is employed, which is first implemented in primary school (This grading system has been changed recently and is started now from secondary school). There is also fierce competition between Iranian students to enter the better schools and universities. In Sweden, by contrast, a 4-point grading system is employed, which is first implemented in secondary school. Some may view this as a more lenient, less nuanced grading system. Since there is greater equality and fewer differences between social classes in Sweden, the competition between students for entry into Swedish schools and universities is not as tough. Thus, it can be argued that there is a larger discrepancy between educational demands and tasks before and after university in Sweden than in Iran. That is, in Sweden, it is possible that the educational tasks of students at university level become more difficult and stressful than their educational tasks at primary/secondary school level. By contrast, in Iran, students are exposed to and prepared for more competitive and stressful educational tasks even at primary/secondary level. This is a speculative idea that needs to be examined more carefully and systematically in future research.

Yet another possible explanation is related to differences between the two samples with regard to employment and marital situations. The Swedish students were more often in paid employment than the Iranian students. They were also more often married or cohabiting than their Iranian counterparts. Having work outside university, and managing work and family demands, in addition to performing the educational tasks required at university can be very stressful. The present study shows very clearly that the greatest differences between the Swedish and Iranian samples with regard to academic stress lay in difficulties outside class and managing work, family and leisure activities. This is in line with 
research showing that, if working during university is detrimental, individuals who need to work in order to pay tuition fees or finance living costs may be at a disadvantage compared with students from wealthier backgrounds, and also that work-study-based financial aid programs may have certain undesirable side-effects (Stinebrickner \& Stinebrickner, 2003).

\section{Conclusion and implications for future research}

In sum, our present research into academic stress and its sources among Swedish and Iranian undergraduate students found that Swedish students experienced more academic stress as a whole. This derived from three sources: difficulties in class, difficulties outside class, and jointly managing work, family and leisure activities. However, no cultural differences were found in terms of interacting with the administration, teachers and friends at the university. The cultural differences can be explained on an individualist-collectivist dimension, but there are also alternative explanations, such as differences in educational systems, involvement in work, and marriage. A psychological explanation for these findings is that people can be thought of as emergent properties. The cultural systems in which individuals reside are an embodiment of different components of that system. The promotion of health and the prevention of ill-health require further exploration of these issues. A research focus on variables needs to be complemented with regard to the individual cases that provide data on those variables.

\section{Acknowledgements}

We would like to thank all Iranian and Swedish students who participated in this study. We are also thankful to Maria Rydström, Mikael Glännström and Jakob Nilsson for data collection in Sweden.

\section{References}

Abouserie, R. (1994). Source and levels of stress in relation to locus of control and self-esteem in university students. Educational Psychology: An International Journal of Experimental Educational Psychology, 14 (3), 323-330. http://dx.doi.org/10.1080/0144341940140306

Archer, T., Adrianson, L., Plancak, A., \& Karlsson, E. (2007). Influence of affective person cognition-mediate emotional processing: need for empowerment. The European journal of psychiatry, 21(4), 248-262. http://dx.doi.org/10.4321/S0213-61632007000400002

Bergman, L. R., Magnusson, D., \& El Khouri, B. M. (2003). Studying individual development in an interindividual context: A person-oriented approach. Psychology Press. ISBN 0-8058-3129-0

Bergman, L. R., \& Trost, K. (2006). The person-oriented versus the variable-oriented approach: Are they complementary, opposites, or exploring different worlds? Merrill-Palmer Quarterly, 52(3), 601-632. http://dx.doi.org/10.1353/mpq.2006.0023

Bradley, K., \& Ramirez F. O. (1996). "World Polity and Gender Parity: Women's Share of Higher Education1965-1985. In: A. M. Pallas (Ed.), Research in Sociology of Education and Socialization, Vol. 11, 63-91. Greenwich,CT: JAI Press.

Buddington, S. A. (2002). Acculturation, psychological adjustment (stress, depression, self-esteem) and the academicachievement of Jamaican immigrant college students. International Social Work, 45(4): 447-465. http://dx.doi.org/10.1177/00208728020450040401

Chartrand, J. M. (1992). An empirical test of a model of nontraditional student adjustment. Journal of Counseling Psychology 39(2): 193-202. http://dx.doi.org/10.1037/0022-0167.39.2.193

Chentsova-Dutton, Y., \& Tsai, J. L. (2010). Self-focused attention and emotional reactivity: The role of culture. Journal of Personality and Social Psychology, 98(3), 507-519. http://dx.doi.org/10.1037/a0018534

Chua, H. F.,Boland, J. E. \& Nisbett, R. E. (2005). Cultural variation in eye movements during scene perception. Proceedings of the National Academy of Sciences. 102 (35), 12629-12633. http://dx.doi.org/10.1073/pnas.0506162102

Compton, W. C. (2005). Positive psychology. Thomson Wadsworth. ISBN 13: 978-0-534-64453-6

Felsten, G., \& Wilcox, K. (1992). Influences of stress and situation-specific mastery beliefs and satisfaction with social support on well-being and academic performance. Psychological Reports, 70(1): 291-303. http://dx.doi.org/10.2466/pr0.1992.70.1.291

Dahlin, M., Joneborg, N., \& Runeson, B. (2005). Stress and depression among medical students. Medical Education, 39, 594-604. http://dx.doi.org/10.1111/j.1365-2929.2005.02176.x

Diener, E., Wirtz, D., Tov, W., Kim-Prieto, C., Choi, D. W., Oishi, S., \& Biswas-Diener, R. (2010). New 
well-beingmeasures: Short scales to assess flourishing and positive and negative feelings. Social Indicators Research, 97(2), 143-156. http://dx.doi.org/10.1007/s11205-009-9493-y

Gall, T. L., Evans, D. R., \& Bellerose, S. (2000). Transition to first-year university:patterns of change in adjustment across life domains and time. Journal of Social and Clinical Psychology 19(4): 544-567. http://dx.doi.org/10.1521/jscp.2000.19.4.544

Gillock, K. L., \& Reyes, O. (1999). Stress, support, and academic performance of urban, low income, Mexican-American adolescents. Journal of Youth and Adolescence 28(2): 259-282. http://dx.doi.org/10.1023/A:1021657516275

Grossmann, I., Ellsworth, P.C., Hong, Y-y. (2012). Culture, attention, and emotion. Journal of Experimental Psychology: General, 141(1), 31-36. http://dx.doi.org/10.1037/a0023817

Grossman, I. \& Kross, E. (2010). The impact of culture on adaptive versus maladaptive self-reflection. Psychological Science, 21, 1150-1157. http://dx.doi.org/10.1177/0956797610376655

Heine, S. J., Lehman, D. R., Markus, H. R. \& Kitayama, S. (1999). Is there a universal need for positive self-regard? Psychological Review, 106, 766-794. http://dx.doi.org/10.1037/0033-295X.106.4.766

Heine, S. J. \& Hamamura, T. (2007). In Search of East Asian Self-Enhancement. Personality and Social Psychology Review, 11 (1), 4-27. http://dx.doi.org/10.1177/1088868306294587

Heine, S. J., Kitayama, S. \& Hamamura, T. (2007). Inclusion of additional studies yields different conclusions: Comment on Sedikides, Gaertner \& Vevea (2005), Journal of Personality and Social Psychology. Asian Journal of Social Psychology, 10 (2), 49-58. http://dx.doi.org/10.1111/j.1467-839X.2007.00211.x

Jobson, L. (2011). Cultural differences in levels of autonomous orientation in autobiographical remembering in posttraumatic stress disorder. Applied Cognitive Psychology, 25(2), 175-182. http://dx.doi.org/10.1002/acp.1660

Kitayama, S., Markus, H. R., \& Kurokawa, M. (2000). Culture, emotion, and well-being: Good feelings in Japan and the United States. Cognition and Emotion, 14 (1), 93-124. http://dx.doi.org/10.1080/026999300379003

Kormi-Nouri, R., Farahani, M., \& Trost, K. (2013). The roles of positive and negative affect in well-being among Swedish and Iranian university students. The Journal of Positive Psychology, 8(5), 435-443. http://dx.doi.org/10.1080/17439760.2013.823511

McDaniel, A. (2010). "Cross-National Gender Gaps in Educational Expectations: The Influence of National-Level Gender Ideology and Educational Systems." Comparative Education Review 54(1): 27-50. http://dx.doi.org/10.1086/648060

McDaniel, A. (2011). "The Gender Gap in Higher Education: A Cross-National Analysis of 131 Countries." Working paper.

Garcia \& MacDonald. "Two Different Approaches to The Affective Personality Profiles Model: Median Split and Cluster Analysis." Working paper.

Mallinckrodt, B. (1988). Student retention, social support, and dropout intention: Comparison of black and white students. Journal of College Student Development, 29(1): 60-64.

Markus, H., \& Kitayama, S. (1991). Culture and the self: Implications for cognition, emotion, and motivation. Psychological Review, 98(2), 224-253. http://dx.doi.org/10.1037/0033-295X.98.2.224

Markus \& Kitayama (1994). A collective fear of the collective: Implications for selves and theories of selves. Personality and Social Pyschology Bulletin, 20(5), 568-579. http://dx.doi.org/10.1177/0146167294205013

Masuda, T. \& Nibsett, R. E. (2006). Culture and change blindness. Cognitive Science, 30(2), 381-399. http://dx.doi.org/10.1207/s15516709cog0000_63

Mezulis A. H, Abramson L. Y, Hyde J. S, Hankin B. L. (2004). Is there a universal positivity bias in attributions? A meta-analytic review of individual, developmental, and cultural differences in the self-serving attributional bias. Psychological Bulletin, 130 (5), 711-747. http://dx.doi.org/10.1037/0033-2909.130.5.711

Misra, R. \& Castillo, L. G. (2004). Academic stress among college students:comparison of American andinternational students. International Journal of Stress Management, 11(2), 132-148. http://dx.doi.org/10.1037/1072-5245.11.2.132

Misra, R. \& Mckean, M. (2000). College students' academic stress and its relation to their anxiety, time management, and leisure satisfaction. American Journal of Health Studies, 16 (1), 41-51. 
Moritsugu, J., \& Stanley, S. (1983). Minority status as a stressor. In: Felner, R. D. (eds.), Preventive Psychology: Theory, Research, Practice. Pergamon, New York, NY.

Pekkarinen, T. (2008). Gender differences in educational attainment: Evidence on the role of tracking from a Finnish quasi-experiment, Scandinavian Journal of Economics, 110 (4), 807-825. http://dx.doi.org/10.1111/j.1467-9442.2008.00562.x

Perrine, R. M. (1999). Stress and college persistence as a function of attachment style. Journal of the First Year Experience and Students in Transition, 11(1): 25-38.

Petrie, T. A., and Stoever, S. (1997). Academic and nonacademic predictors of female Student athletes' academic performance. Journal of College Student Development 38(6): 599-608.

Pressman, S. D., Gallagher, M. W., \& Lopez, S. J. (2013). Is the emotion-health connection a "first-world problem"? Psychological science, 24 (4), 544-549. http://dx.doi.org/10.1177/0956797612457382

Pritchard, M. E., \& Wilson, G. S. (2003). Using emotional and social factors to predict student success. Journal of College Student Development 44(1): 18-28. http://dx.doi.org/10.1353/csd.2003.0008

Realo, A. (2003). Comparison of public and academic discourses: Estonian individualism and collectivism revisited. Culture \& Psychology, 9(1), 47-77. http://dx.doi.org/10.1177/1354067X03009001004

Russell, R.K., \& Petrie, T.A. (1992). Academic adjustment of college students: Assessment and counseling. In: Lent, R. W. (eds.), Handbook of Counseling Psychology, 2nd ednd edition, John Wiley and Sons, Inc, Hoboken, NJ, pp.485-511.

Sandler, M. E. (2000). Career decision-making self-efficacy, perceived stress, and an integrated model of student performance: A structural model of finances, attitudes, behavior, and career development. Research in Higher Education 41(5): 537-578. http://dx.doi.org/10.1023/A:1007032525530

Schofer, E. \& Meyer. J. (2005). "The World-Wide Expansion of Higher Education in the Twentieth Century." American Sociological Review 70 (6): 898-920. http://dx.doi.org/10.1177/000312240507000602

Sedikides, C., Gaertner, L. \& Vevea, J. L. (2007). Evaluating the evidence for pancultural self-enhancemen Asian Journal of Social Psychology (2007), 10 (3), 201-203. http://dx.doi.org/10.1111/j.1467-839X.2007.00227.x

Smedley, B. D., Myers, H. F., \& Harrell, S. P. (1993). Minority-status stresses and the college adjustment of ethnic minority freshmen. Journal of Higher Education 64(4): 434-452. http://dx.doi.org/10.2307/2960051

Stinebrickner, T. R. \& Stinebrickne, R. (2003). Working during school and academic performance. Journal of Labor Economics, 21 (2), 473-491. http://dx.doi.org/10.1086/345565

Struthers, C. W., Perry, R. P., \& Menec, V. H. (2000). An examination of the relationship among academic stress, coping, motivation, and performance in college. Research in Higher Education 41(5): 581-592. http://dx.doi.org/10.1023/A:1007094931292

Toews, J. A., Lockyer, J. M., Dobson, D. J. G., Simpson, E., Brownell, A., Keith, W.,Brenneis, F., Macpherson, K. M., \& Cohen, G. S. (1997). Analysis of stress levels among medical students, resistant and graduate students at four Canadian schools of medicine. Academic Medicine, 72(11), 997-1002. http://dx.doi.org/10.1097/00001888-199711000-00019

Triandis, H.C. (1990). Cross-cultural studies of individualism and collectivism in: Berman, J.J. (ed.) Cross-cultural perspectives. Nebraska symposium on motivation 1989. Nebraska University Press, London, UK.

Vargha, A., Torma, B., \& Bergman, L.R. (2014). ROPstat: A general statistical package useful for conducting person-oriented analyses. Report No. 15. Stockholm University.

Watson, D., Clark, L. A., \& Tellegen, A. (1988). Development and validation of brief measures of positive and negative affect: The PANAS scales. Journal of Personality and Social Psychology, 54(6), 1063-1070. http://dx.doi.org/10.1037/0022-3514.54.6.1063

Zajacova, A., Lynch, S.M., \& Espenshadet, T.J. (2005). Self-efficacy, stress and academic success in college. Research in Higher Education, 46 (6), 677-706. http://dx.doi.org/10.1007/s11162-004-4139-z

Zhang, Z., \& RiCharde, R. S. (1998). Prediction and Analysis of Freshman Retention. Minneapolis, MN: Paper presented at the Annual Forum of the Association for Institutional Research. ERIC Number: ED422814 


\section{Appendix}

Please state how stressful these tasks are for you, from $0=$ not at all stressful to $10=$ extremely stressful.

Task Not at all stressful

$0 \quad 1$

23

4

6

Extremely stressful

\section{Difficulties in class:}

My parents' expectations of my grades

Doing well in exams

Having more than one test in the same week

Taking good class notes

Getting the grades I want

Doing well in my toughest class

Maximum score $=60$

\section{Difficulties outside class:}

Studying

Keeping up with required reading

Writing term papers

Getting papers done on time

Preparing for exams

Improving my reading and writing skills

Researching term papers

Understanding my textbooks

Maximum score $=80$

\section{Difficulties in interacting with the university:}

Asking questions in class

Understanding my professors (teachers)

Making friends at school

Talking to my professors (teachers)

Getting help and information at school

Talking to college staff

Participating in class discussions

Understanding college regulations

Maximum score $=80$

Difficulties in managing different domains:

Managing both school and work

Managing both school and leisure activities

Managing time efficiently

Getting along with family members

Having enough money

Finding time to studyMaximum score $=60$ 